\title{
A Technical, Economic and Environmental Assessment of Decentralized Systems Connected to the Algerian Grid. Case Study: Adrar Site
}

\author{
Djohra Saheb Koussa ${ }^{1, *}$, Mustapha Koussa ${ }^{1}$, Seddik Hadji ${ }^{2}$ \\ ${ }^{1}$ Centre De DEveloppement Des Energies Renouvelables, BP62 Route De L'Observatoire Bouzareah, Alger 16340, AlgErie \\ ${ }^{2}$ Laboratoire Des Technologies Industrielle Et De L'Information, UniversitE A. Mira De Bejaia, Targa Ouzemour, Bejaia 06000, Algeria
}

\begin{abstract}
This work is aimed to study the wind and photovoltaic power systems connected to the conventional grid. The main interest of such a system is in its own production within the place of consumption, hybridization, and the pooling of resources and the contribution to the environmental protection. To ensure a better management system energy models have been developed for determining the power that subsystems can deliver under given weather conditions Simulation of different subsystems is performed using MATLAB-SIMULINK. The economic and environmental study is developed using the HOMER software. From an economic standpoint, this allows to compare the financial constraints on each system on the Adrar site $(27.59 \mathrm{~N}, 0.11 \mathrm{~W})$ located in the North-South of Algeria. It also permits to size and select the most optimal system based on two parameters, namely the cost and effectiveness. From an environmental perspective, this study allows us to highlighting the role of renewable energy in reducing emissions of greenhouse gas emissions.
\end{abstract}

Keywords Wind, Photovoltaic, Grid, Economy, Environment, MATLAB, HOMER

\section{Introduction}

Recently, a growing number of organizations have begun to consider renewable energy and industries related to their production, distribution and services as opportunities rather than regulations[1-6]. Several factors including Kyoto Protocol, alarming reports by Intergovernmental Panel on Climate Change (IPCC) and Copenhagen climate change conference (COP15) have contributed to this change in perspective, and many believe that the trend will continue such that it is of paramount importance to prepare for the "green race" immediately. Algerian government and companies are not exceptions; in fact, they have recently been intensifying efforts towards promoting economic growth via supporting green industries. Examples of such efforts include plans for establishing numerous energy clusters in regions like the proposed wind farm energy production with a capacity of 10 megawatts that were launched in Adrar and the hybrid plant in the region of Hassi R'Mel (Laghouat) made and commissionined since February 2011. Similar projects, environmentally friendly and producing clean and renewable energy, are made available for the areas of Timimoune and Kunta Zaouiet encouraging the use of renewable energy[7,8].

* Corresponding author:

dkoussa@cder.dz (Djohra Saheb Koussa)

Published online at http://journal.sapub.org/ep

Copyright (C) 2012 Scientific \& Academic Publishing. All Rights Reserved
However, electrical energy from wind and PV is consider ed the most promising renewable energy to be developed to replace coal, oil, gas and even nuclear. Anytime, any process of transformation of one form of energy into another usable form is complex. It must integrate a number of advantages and disadvantages of different types, technical, economic and environmental. Thus, the techno - economic and environmental results, presented in this paper allows judging objectively[9].

\section{Presentation of the Different Systems of Distributed Generation from Re- newable Energy}

\subsection{Standalone Systems}

For a standalone installation, the energy produced by the photovoltaic solar panels or by the wind generator is used immediately (pumping, ventilation, lighting, refrigerator etc. ) or stored in batteries for later use. The produced current is directly fed to the to the consuming equipment or converted via an inverter to supply devices that require $\mathrm{AC}$ power[10,11].

\subsection{Multi-Source Hybrid Systems}

These systems supply electricity that is often used at remote sites and are built by coupling different sources of 
production of electrical energy such as wind, solar and others. They also allow a more reliable supply of electricity. Nearly two billion people are not connected to the utility grid (44\% of the world population). Thus, the development of hybrid systems conversion of renewable energy will undoubtedly help to solve many social problems, especially in poor countries and open up vast commercial markets[10] and[12-15].

\subsection{Distributed Systems Connected to the Grid}

These are medium and large systems of grid connected [16-19] and running in general over the sun or wind (Fig.1).

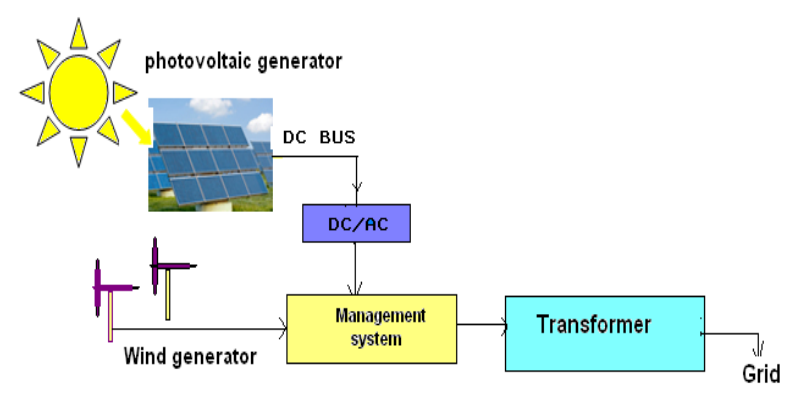

Figure 1. Decentralized installation connected to the grid

\subsubsection{Problems in the Functioning of Decentralized Sys-}

tems [20]

The major difficulty associated with decentralized energy sources is that they generally do not participate in ancillary services (voltage control, frequency, ability to operate in stand-alone mode, etc...). This is especially true for renewable energy sources whose power flow is unpredictable and very volatile. The integration of decentralized generation in networks raises the following problems:

- Random and unpredictable production (wind, solar);

- Lack of power-frequency control;

- No voltage adjustment;

- Sensitivity to voltage dips;

- Sensitivity to changes in important primary source (wind, solar).

The failure to participate in system services brings this type of source to behave as passive generators from the electrical generation point of view. The penetration of distributed generation must be limited by 20 to $30 \%$ of the consumed power in order to guarantee acceptable system stability[21].

\section{Application Model of a Technical Study and Environmental-Economic Decentralized Systems Connected to the Grid in Algeria. Case Study Adrar}

As an application, the Adrar site has been chosen and the following data are used as input :
- The hourly global and diffuse radiation measured on a horizontal plane and the ambient temperature. From the data collected on a horizontal plane, the components of the solar irradiance have been projected on to the surface of a photovoltaic panel. Moreover, the inclination of the used solar panel corresponds to the yearly optimum slope.

- The measured wind speeds and the electromechanical characteristics of a wind turbine of the VESTAS 47-660 type. It is a three-blade model with a diameter of $46 \mathrm{~m}$, a speed multiplier ratio of 50.5 and the hub height is $100 \mathrm{~m}$ [22]. Moreover, the power produced by this wind turbine has been calculated using the power curve provided by the manufacturer.

\subsection{Power Produced By the Photovoltaic Generator}

For calculating the output characteristics of the photovoltaic system, a program has been developed which requires the global incident radiation and the air temperature as main input data.

So, the research unit in renewable energy U.R.E.R. of Adrar provided a full year of hourly measured values of global and diffuse irradiation on a horizontal plane together with those related to the ambient temperature2. From the global radiations on the horizontal plane collected data and based on the equations given in[23], the developed program calculates the overall incident irradiation on the surface of the photovoltaic panel. These latter and the ambient temperatures are used to calculate the power and current delivered by the PV generator. The obtained results are presented in Fig. 2.

\subsection{Power Produced By the Wind Generator}

Generally to calculate the power generated by a wind turbine, the data drawn from the main characteristic $\mathrm{p}=\mathrm{f}(\mathrm{v})$ and supplied by the manufacturer has been used. In this study, using the equations given in[23], the hourly values of wind speed on the Adrar, site are calculated at the hub height of the machine[23]. These are used to determine the machine performance. The results are as follows:

- In Fig. 3.a is presented the evolution of hourly wind speeds;

- In Fig. 3. b and c are presented respectively the active and reactive power developed at the asynchronous machine;

- In Fig. 3.d is presented the current delivered by the windgenerator.

\subsection{Electrical Energy Injected into the Grid}

The power delivered by each of the system devices (photovoltaic or wind) should be managed, in such a way that the surplus of power produced by any part of them is conducted to the grid without giving rise to any phenomena leading to a disturbance of any of these devices. For each hour of the year $h$, the amount of electrical energy available at the transformer connected to the grid is evaluated by[24]:

$$
P_{A C_{-} h}=\left(P_{p v-h} \cdot \eta_{I N V}+P_{W-h}\right) \cdot \eta_{T R}
$$


where $\eta_{\mathrm{INV}}$ is the inverter efficiency rate, modelled as a variable depending on the power delivered by the inverter, $\eta_{\mathrm{TR}}$ is the efficiency rate of the transformer connected to the electrical grid, including the losses of power in the transmission lines, $\mathrm{P}_{\mathrm{w}-\mathrm{h}}$ is the power generated by the windgenerator in an hour $(\mathrm{W})$ and $\mathrm{P}_{\mathrm{pv}-\mathrm{h}}$ is the power generated by the photovoltaic generator in an hour (W) .

However, the amount of power that can be injected each hour into the grid, $\mathrm{P}_{\mathrm{EE}-\mathrm{h}}(\mathrm{W})$, cannot be superior to the allowed evacuation capacity at the point of the connection to the grid, $\mathrm{P}_{\text {MAX-GRID }}(\mathrm{W})[24]$ :

$$
P_{E E-h}=\min \left(P_{M A X-G R I D}, P_{A C-h}\right)
$$

$\mathrm{P}_{\text {MAX-GRID }}(\mathrm{W})$ is the maximum of power evacuation value allowed, that the Algerian law fixes within 20 to $30 \%$ of the thermal limit of the line at the point of connection.

The amount of energy to be injected into the grid obtained from the photovoltaic generator $\left(\mathrm{P}_{\mathrm{EE}-\mathrm{PV}-\mathrm{h}}\right)$ and the wind generator $\mathrm{P}_{\mathrm{EE}-\mathrm{w}-\mathrm{h}}$ will be calculated as indicated by the following flowchart:

The results obtained in the case of the previously described scenario are represented in Fig. 5 which shows that the hourly produced power injected into the grid is lower than $\mathrm{P}_{\text {MAX-GRID. }}$
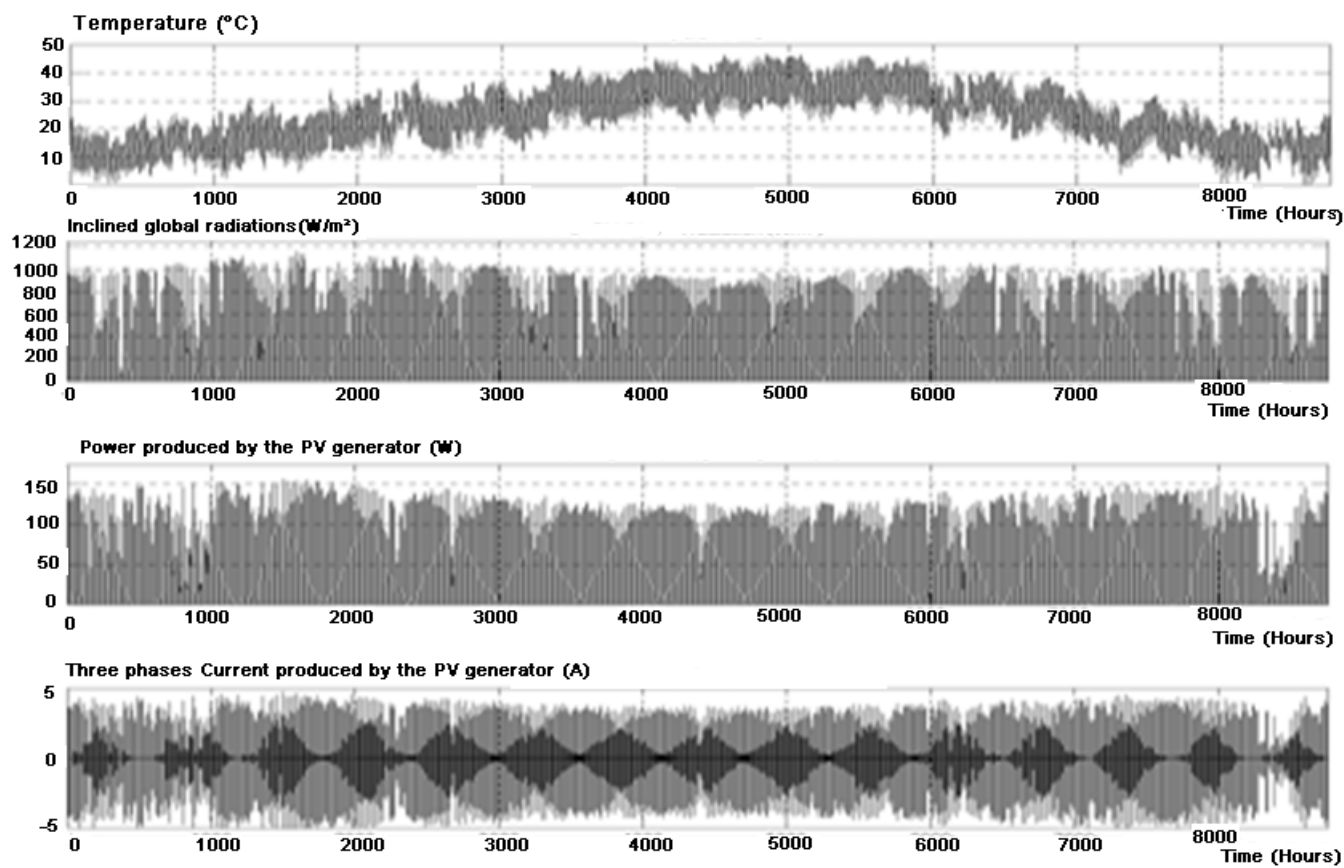

Figure 2. Representation of climatic characteristics, power and current produced by the photovoltaic module BP SX $150 \mathrm{~S}$ installed on the Adrar site
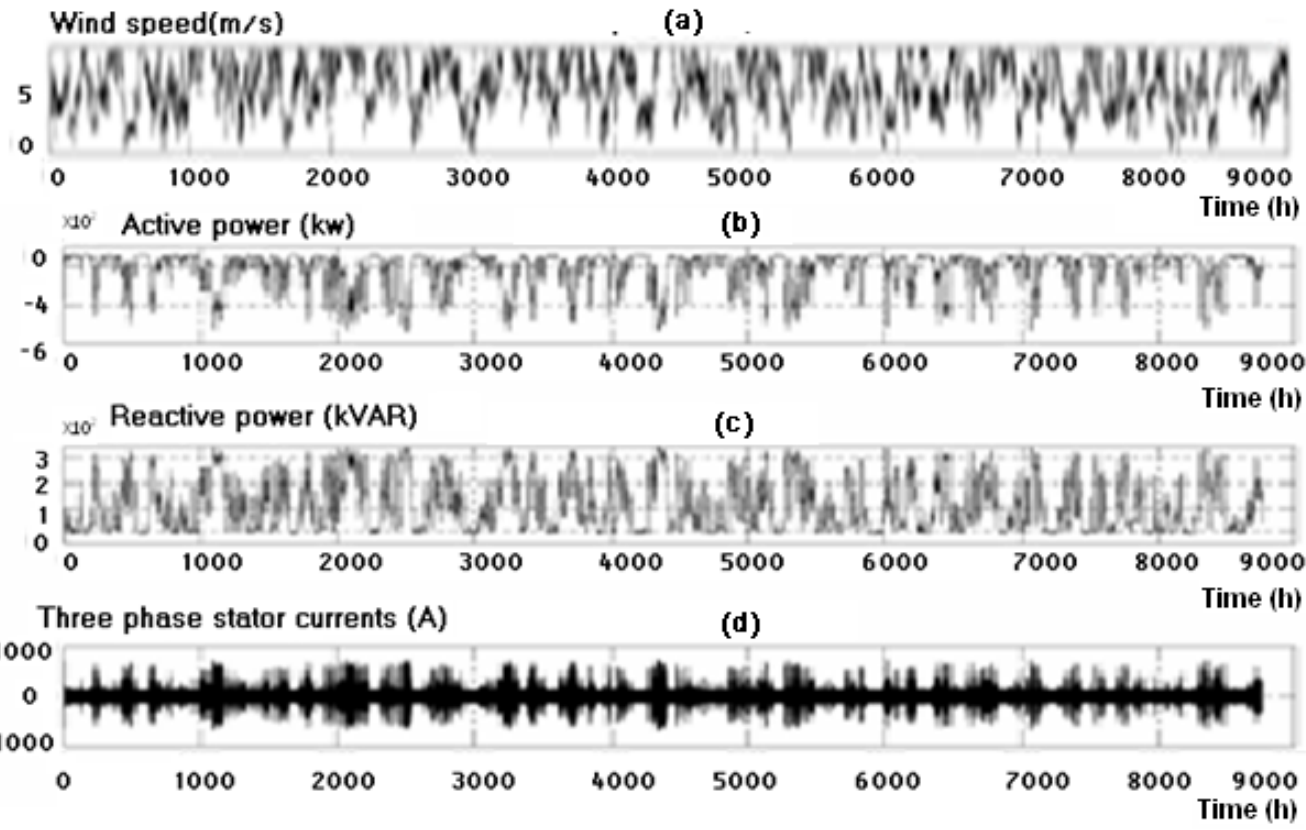

Figure 3. Simulation results 


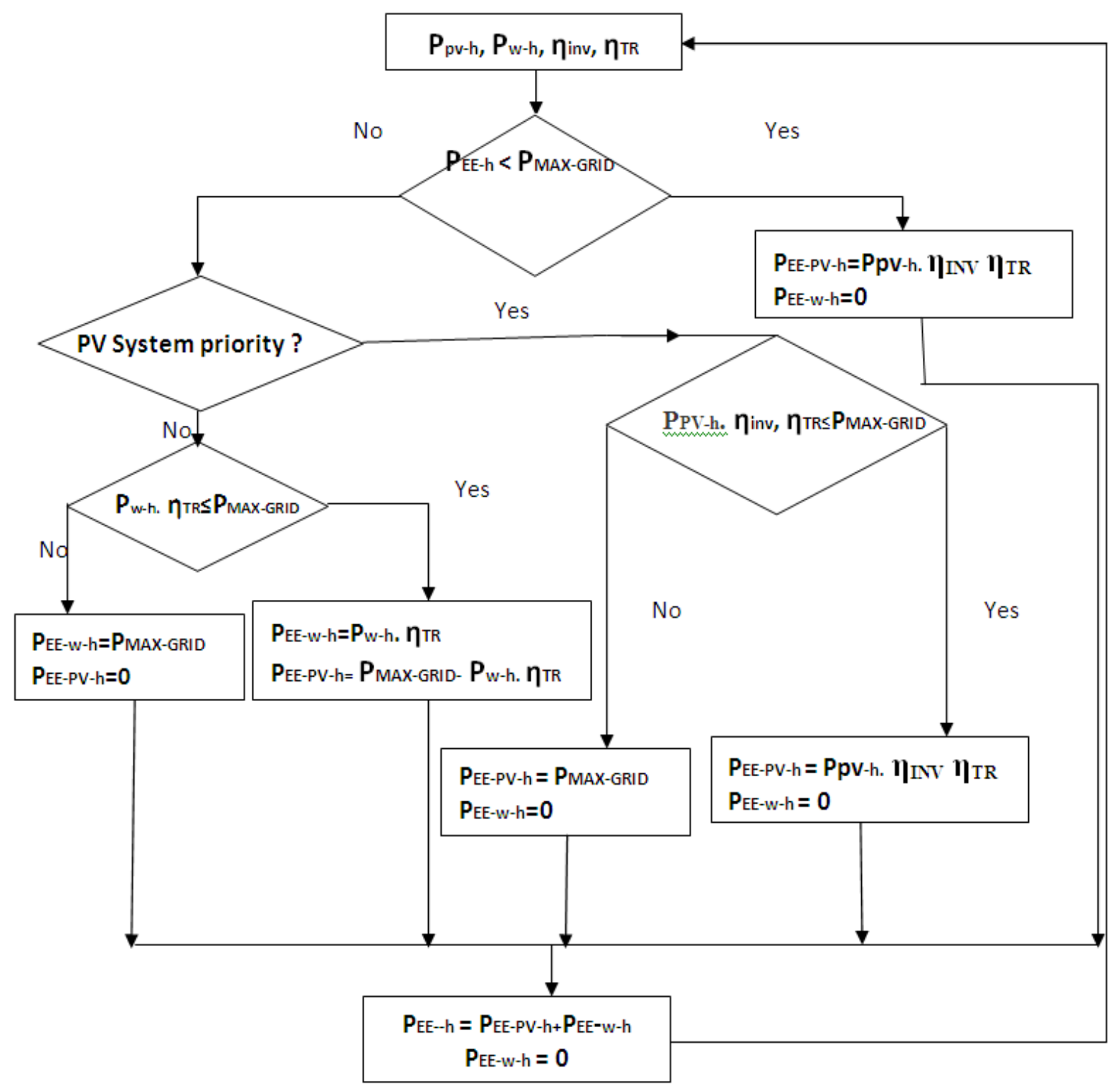

Figure 4. Flowchart for calculating the amount of power to be inject into the grid

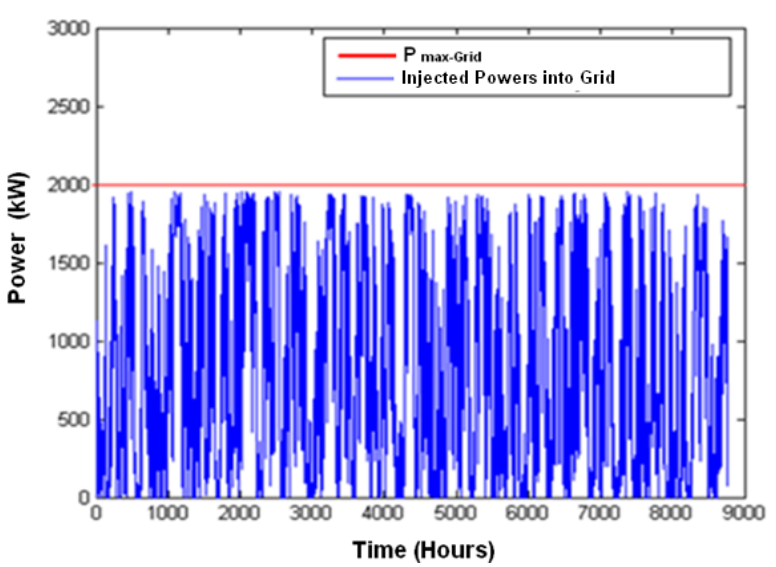

Figure 5. Powers injected into the Grid

\subsection{Total Annual Production}

The contribution of each part of the equipment of the hybrid system (PV-wind-grid) to meet a specific load of 95MWh /day with a peak value of 7.7 MW is shown in Fig. 6.
It is to be noted that the PV generator produces only 365 MWh /year and covers only $1 \%$ of the load. The wind generator, in turn, produces $7.225 \mathrm{MW}-h$ /year which constitute nearly $21 \%$ in coverage against a covered load of $78 \%$ (27.225 MWh/year) provided by the conventional electricity $\operatorname{grid}[25]$.

\section{-Wind system = Photovoltaic system " Grid}

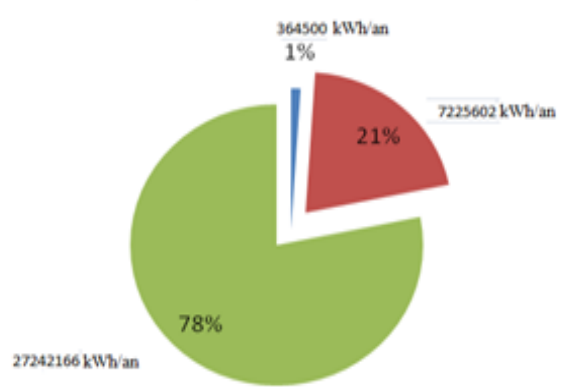

Figure 6. Structure of the production system (PV-Wind-Grid) 
The average annual energy resources solar irradiance and wind speed evaluate, respectively, to $5.72 \mathrm{kWh} / \mathrm{m}^{2} /$ day and $6 \mathrm{~m} / \mathrm{s}$ and the cost per $\mathrm{kWh}$ produced by the grid is 0.4 $\$ / \mathrm{kWh}[20]$.

\subsection{Hours of Operation}

Fig.7 represents the operation hours of each of the renewable energy equipments of the hybrid PV-wind-Grid system. It is found that the wind generator section monopolizes the largest parts with a $48 \%$ rate of the total, followed by the PV generator and inverter with $26 \%$ each one.

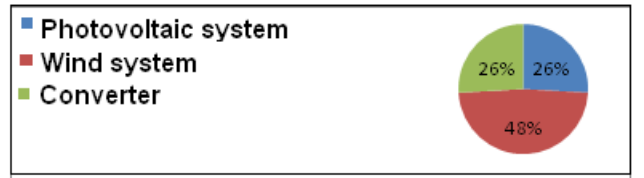

Figure 7. Distribution of operation hours of each of the renewable energy equipment of the hybrid PV-wind-Grid system

\subsection{Economic Aspects}

Table 1. Cost comparison between a standard system (Grid) and an hybrid system (PV-wind-Grid)

\begin{tabular}{c|c|c}
\hline Cost & $\begin{array}{c}\text { Conventional } \\
\text { system (Grid) }\end{array}$ & $\begin{array}{c}\text { Hybrid system } \\
\text { (PV-wind-Grid) }\end{array}$ \\
\hline $\mathrm{NPC}(\$ / \mathrm{an})$ & 177714200 & 177090600 \\
\hline $\mathrm{COE}(\$ \mathrm{kWh})$ & 0,4 & 0,399 \\
\hline
\end{tabular}

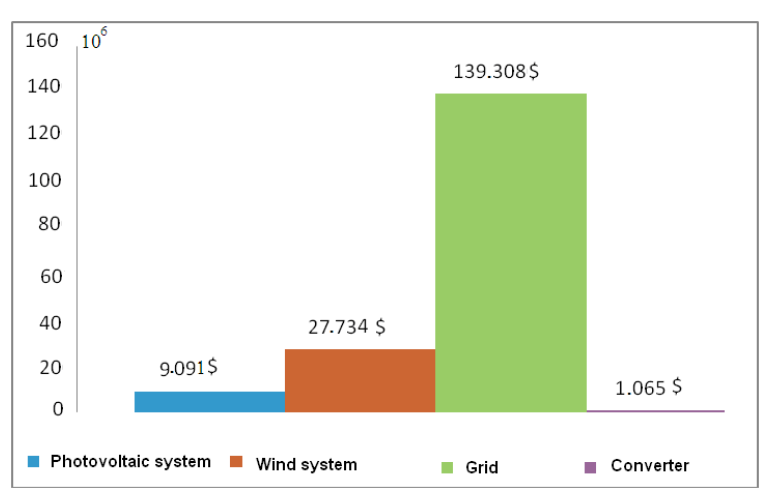

Figure 8. Net present cost

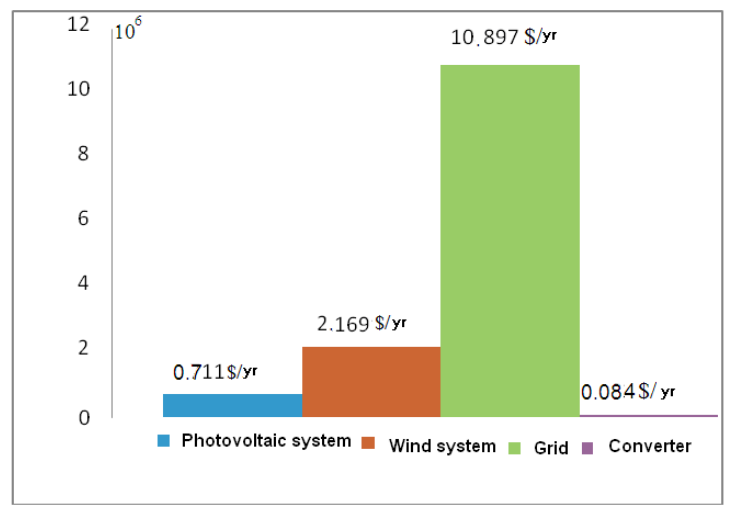

Figure 9. Annual Net Cost

From the economic point of view, it is found that the system comprised of a $200 \mathrm{~kW}$ rated photovoltaic system and three wind turbines rated $660 \mathrm{~kW}$ can cover $22 \%$ of the electric energy demand and has a net present cost (NPC) of $\$ 177$ million and a cost of energy per kilowatt hour (COE) of $\$ 0.399 / \mathrm{kWh}$. A comparative economic analysis between the conventional and the optimized system (PV-wind system) has been made and the results presented in Table 1 [25]. From these results, it is noticed that the system (PV-wind-grid) is more economical than the conventional system if the price per $\mathrm{kWh}$ produced by the latter is set to $\$ 0.4 / \mathrm{kWh}$. However, the discounted net cost was calculated for a 25 years lifetime of the project and on the basis of an interest rate of $6 \%$. Figs 8 and 9 show the details of the costs of each system and the related annual costs[20].

\subsection{Environmental Aspects}

The results regarding the environmental effect of each configuration (conventional grid system and hybrid system: Photovoltaic-wind-Grid) obtained and regarding the Adrar site are shown in Fig. 10 [25]. In these figures are presented the quantities of the main gases that are harmful to the environment including $\mathrm{CO} 2, \mathrm{SO} 2$ and $\mathrm{NOx}$. From these results, it is found that the PV-wind-Grid hybrid system produces a reduction rate of the carbon dioxide gas, sulfur dioxide and nitrogen oxide respectively of $20 \%, 22 \%$ and $22 \%$, respectively, compared to the quantities produced by the conventional system [20].
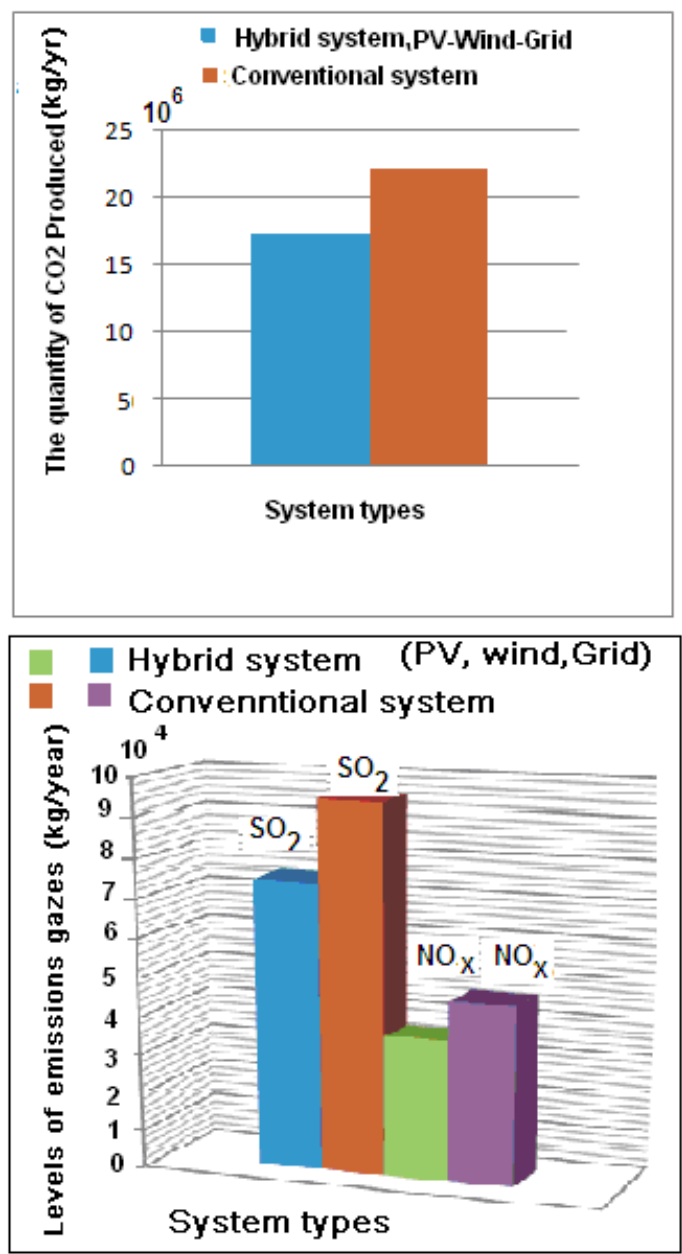

Figure 10. The quantities of the polluting gases produced by an hybrid system (PV-wind-Grid) and a conventional system 


\section{Conclusions}

This study relates to the technical, economic and environmental impact of decentralized systems coupled to the grid with the appropriate management of energy, through which energy models have been developed.

The most significant results are as follows:

1 - The power that any of the sub systems can provide depends on the weather of the considered site;

2 - The solar array covers only $1 \%$ of the total load consumption. The wind generator contribution rate to energy production is about $21 \%$ while $78 \%$ are supplied by the conventional electricity grid

3 - From an the economic point of view, it is found that for the Adrar site, which is characterized by high wind potential, the hybrid system is competitive with conventional system for a WCC of the energy produced by the network equal to $\$ 0.4 / \mathrm{kWh}$ as the WCC's hybrid system is equal to $\$ 0,399 / \mathrm{kWh}$ with an average wind speed greater than or equal to $6 \mathrm{~m} / \mathrm{s}$;

4 - From an environmental standpoint, emissions of greenhouse gases $\left(\mathrm{CO}_{2}, \mathrm{SO}_{2}\right.$ and $\left.\mathrm{NO}_{\mathrm{x}}\right)$ are reduced by 20 to $22 \%$ in the case of a hybrid system, compared with the conventional system.

\section{REFERENCES}

[1] Jamin Koo, Kyungtae Park, Dongil Shin, En Sup Yoon," Economic evaluation of renewable energy systems under varying scenarios and its implications to Korea's renewable energy plan". Appl Energy 2011;88:2254-.2260.

[2] World Energy Outlook. Published by IEA; 2008.

[3] Hofman K, Li X. "Canada's energy perspectives and policies for sustainable development”. Appl Energy 2009;86:407-15.

[4] Weigt H. "Germany's wind energy: the potential for fossil capacity replacement and cost saving". Appl Energy 2009;86:1857-63.

[5] Khan SA, Rashmi, Hussain MZ, Prasad S, Banerjee UC." Prospects of biodiesel production from microalgae in India". Renew Sustain Energy Rev 2009;13:2361-72.

[6] Yoon ES. A review on sustainable energy: recent developments and future prospects of dimethyl ether (DME). In: 10th International symposium on process systems engineering (PSE). Bahia, Brazil; 2009.

[7] http://www.ampaireo.fr/panneaux-photovoltaiques.html

[8] http://www.algerie-news.com/algerie-info/adrar-lancement-d es-travaux-du-projet-de-la-ferme-eolienne/

[9] André Ducluzaux, "L'énergie électrique d'origine éolienne“, conférence sur l'énergie, Grenoble 2004

[10] Panayiotou Gregoris; Kalogirou Soteris; Tassou Savvas, «Design and simulation of a PV and a PV-Wind standalone energy system to power a household application" RENEWABLE ENERGY Volume: 37 Issue: 1 Pages: 355-363 JAN 2012.
[11] S.M. Shaahid," Review of research on autonomous wind farms and solar parks and their feasibility for commercial loads in hot region", Renewable and Sustainable Energy Reviews 15 (2011) 3877-3887.

[12] Elhadidy MA, Shaahid SM. "Parametric study of hybrid (wind-solar-diesel) power generating systems". Renewable Energy 2000; 21(2):129-39. October 2000.

[13] Shaahid SM, Elhadidy MA. "Technical and economic assessment of grid independent hybrid photovoltaic-diesel-battery power systems for commercial loads in desert environments". Renewable and Sustainable Energy Reviews, 2007;11:1794-810

[14] D.Saheb-Koussa, M.Haddadi, M.belhamel," Economic and technical study of a hybrid system (wind-photovoltaic-diesel) for rural electrification in Algeria", published in Applied Energy, published in Volume 86, Issues 7-8, July-August 2009, Pages 1024-1030.

[15] Dalton GJ, Lockington DA, Baldock TE. Feasibility analysis of stand-alone renewable energy supply options for a large hotel. Renewable Energy July 2008;33:1475-90.

[16] Ali Naci Celik," Present status of photovoltaic energy in Turkey and life cycle techno-economic analysis of a grid-connected photovoltaic-house" Renewable and Sustainable Energy Reviews"10 (2006) 370-387

[17] Md. Alam Hossain Mondal , Manfred Denich ,"Assessment of renewable energy resources potential for electricity generation in Bangladesh" Renewable and Sustainable Energy Reviews 14 (2010) 2401-2413.

[18] Djohra Saheb-Koussa, Mourad Haddadi, Maiouf Belhamel, Seddik Hadji, Said Nouredine, "Modeling and simulation of the fixed-speed WECS (wind energy conversion system): Application to the Algerian Sahara area", Energy, Volume 35, Issue 10, October 2010, Pages 4116-4125.

[19] Rehman S, El-Amin IM, Ahmad F, Shaahid SM, AlShehri AM, Bakkashwain JM,et al. Feasibility study of hybrid retrofits to an isolated off-grid diesel power plant. Renewable and Sustainable Energy Reviews 2005;11: 635-53. May 2007.

[20] Dj. SAHEB-KOUSSA, « Etude, technique, économique et environnementale des systèmes décentralisés connectés au réseau électrique », thèse de doctorat, ENP Novembre 2011.

[21] Vincent courtecuisse "Supervision d'une centrale multi sources à base d'éoliennes et de stockage d'énergie connectée au réseau électrique“, Thèse de doctorat, Ecole Nationale des Arts et Métiers, Novembre 2008.

[22] Les aérogénérateurs. Cours de 1 STI GE électrotechnique 2008/2009.

[23] D. Saheb-Koussa, M. Haddadi et M. Belhamel, "Contribution à l'étude théorique du comportement d'un système hybride (eolien - photovoltaïque - diesel) de production d'électricité sans interruption"., Afrique SCIENCE, Vol.5, $\mathrm{N}^{\circ} 1,1$ janvier 2009. See: http://ajol.info/index.php/afsci/vew/61704

[24] Rodolfo Dufo-Lopez, José L.Bernal-Augustin, Franklin Mendoza, "Design and economical analysis of Hybrid PV-Wind systems connected to the grid for the intermittent production of hydorgen" Energy Policy, 37(2009) 3082-3095.

[25] HOMER - Getting Started Guide for HOMER Version 2.1. 2005, National Renewable Energy Laboratory, Operated for the U.S. Department of Energy Office of Energy Efficiency and Renewable Energ 